\title{
CALCULATIONS ON ECOLOGICAL FOOTPRINT AS A TOOL FOR LAND USE PLANNING AND DEVELOPMENT ON V4 COUNTRIES
}

\author{
Somaya ABOELNAGAª, Tamás TÓTH ${ }^{b}$, György Iván NESZMÉLYIc \\ ${ }^{a} \mathrm{Ph} . \mathrm{D}$. Candidate Hungarian University of Agriculture and Life Sciences (MATE), Hungary; \\ Lecturer Assistant, Urban Regional Development Dep., Faculty of Urban and Regional Planning, \\ Cairo University, Egypt, e-mail: somayanaga@cu.edu.eg \\ ${ }^{\mathrm{b}}$ Prof. Dr. habil. Tamás Tóth PhD, Professor of the Institute of Sustainable Economy, Kodolányi \\ János University, 1139 Budapest, Frangepán str. 50-56. Hungary; e-mail: \\ Toth.Tamas.Argi@gmail.com \\ ${ }^{c}$ Dr. habil. György Iván Neszmélyi PhD, Professor of the Institute of Commerce, Budapest \\ Business School-University of Applied Sciences, 1155 Budapest, Markó str. 29-31, Hungary; e- \\ mail: Neszmelyi.Gyorgy@uni-bge.hu
}

Cite this article: Aboelnaga, S., Tóth, T., Neszmélyi, G. (2021). Calculations on Ecological Footprint as a tool for land use planning and development on V4 countries. Deturope, 13(1), 24-39.

\begin{abstract}
Land use plan is a fundamental pillar for shaping the future of urban development plans to deal with national and regional issues. There is a merger between land use objectives as a resource and general development objectives to define clearly the importance of a developmental system for comprehensive land-use planning. Most regional plans do not follow integrated system of land-use planning without considering urban settlement in creating the vision and goals of their policies. As a result, most sectoral development plans are created in isolation without systematic consideration of standards and development tools of urban development. Consequently, this study attempts to use ecological footprint to evaluate regional land use in their current situation and in the stages of preparation of urban plans. Therefore, the comparison to human development index in order to figure out the stages clearly to use the proper land use planning approach, using an example of Visegrád countries.
\end{abstract}

Keywords: Ecological footprint, land use planning, regional approaches, Visegrád countries.

\section{INTRODUCTION}

Land use planning is the key for developmental plans; it is necessary to assess the current situation to have an effective plan later. Creating regional plans more effective is not that easy, as in most cases they do not follow integrated system of land-use planning that enhance urban settlement in defining the vision and goals of their policies. As a result, most sectoral development plans are created in isolation without systematic consideration of standards and development tools of urban development. Consequently, there was a need to find a proper measurement tool to assist the decision making for setting effective regional plans for national and regional land use planning, with a sustainable understanding of the regions and their 
opportunities and challenges, also it would be good if that tool use the main elements of sustainable (environment, economics, social). The ecological footprint is the most appropriate evaluation method for measuring the impacts on the different types of land uses as well as the possibility of measuring their developmental implications, as there is a significant relation between it and human development index to move with it from being a pure natural/ environmental indicator to be a developmental indicator. Here, the ecological footprint is referred to as modern standards suitable for land use assessment at existing and proposed stages of urban development plans.

The research methodology applied in this study was the interpretation and understanding in a comprehensive way the ecological footprint as a tool for land use planning on national and regional level. The novelty of our research is derived from the fact that there has not been a research on this issue relating to environmentally developmental recommendations on Visegrád countries based on their ecological footprint. The main method was qualitative research study through documents and reports reviews, and their applications on Visegrád countries. This study also attempts to use a new tool for national and regional land use planning approaches by reviewing the ecological footprint as tools for evaluating regional land use in their current situation and in the stages of preparation of urban plans. Firstly, the study had an overview on the definitions of ecological footprint and biocapacity. Next, it focused on the relation between them, and their principles. Finally, the researchers illustrated some measurement methods and equations of ecological footprint, with an application of Visegrád four.

\section{THEORETICAL BACKGROUND}

All human activities have an impact on the natural environmental. The capacity to control interrelationship conditions the continuity, of different form of activity and the potential for economic and social development (Ira, 2001). Therefore, the ecological footprint and biocapacity equations helps to understand how those activities is changing the natural environment with the economic trends and development process.

The Ecological Footprint is seen as a simple means of comparing the sustainability of resource use among different populations, the amount of land needed to sustain these populations, and to compare with the actual area of productive land inhabited by these populations (Goodal, 1987 and Collins, 2017). According to Lenzen and Murray (2003) ecological footprint could be used to calculate the degree of sustainability by the difference 
between available and required land. The ecological footprint is limited to regional policy and planning tool for environmentally sustainable development, as it does not reveal the effects that actually occur, or the nature and severity of the impacts.

In addition, Wackernagel and Rees (1996) define it as the area of land allocated to meet the consumption of the population and absorb all their waste and the consumption is divided into 5 categories: (food, housing, transport, consumer goods and services). The land is divided into 8 categories: (land and energy, degraded land, gardens, cropland, pastures and managed forests, limited land containing forests, and unproductive areas such as deserts and ice caps Lenzen and Murray (2003).

Moreover, Global Footprint Network, 2012 defines it as the tool that measures the relationship between human needs of products and services, with the ecosystem including the productive lands and water areas required to provide these products. This measure evaluates human demand and availability, as well as the capacity of the ocean. The biosphere area (land and sea ... etc.) available to serve a given range of population with biological capacity is measured (Vasa et al. 2018). An ecological footprint measures the ability to meet human demand from the consumption of multiple environmental resources, and the ability to process for recycling (Borucke et al. 2011).

In the case of Canadian municipalities, they define the ecological footprint as the impact each of us has on nature through our daily lifestyles, a tool that helps us think more clearly about our relationship with the planet, and hence the future, therefore, a good way to measure progress towards the sustainability of societies. Sustainability in this context means achieving a satisfactory life without exceeding the capabilities of regeneration using ecological footprint analysis. It is possible to estimate the amount of land that will be necessary to maintain current levels of consumption of individuals and households. The comparison between the size of the consumption of a certain population and the size of the land required for the production of food, wood, energy and all human consumption, with the ability of these lands to produce, replenish and absorb the waste over the years, and the analysis of the ecological footprint is the sum of all our environmental impacts regardless of where it is exactly (Anielski and Wilson 2005).

From the aforementioned definitions, it is clear that ecological footprint is a measure of the impact of a particular society within a given range, through its human consumption, and all associated wastes and emissions on the ecosystem, in terms of regenerative capacity and sustainability of available resources. 
On the other hand, Biological capacity is the ability of ecosystems to produce beneficial biological materials for society and to absorb waste from humans, using management plans for environmental conservation and mining technologies (Global Footprint Network, 2012). It is important to note that what is considered as valuable biological resources changes from time to time depending on human needs. For example, the use of corn as a fuel for the production of ethanol from cellulose was initially used as source of energy but is currently being replaced by renewable energy.

Biological capacity is usually expressed in the global hectare. For example, Biological capacity of one person (or per capita): There are 12 billion hectares of biological land for productive land and water on this planet in 2008. The division of the output on the population of that year (6.7 million inhabitant), gives 1.79 global hectares per person (gha/person).

The relation between Ecological Footprint and Bio-capacity: by comparing the biological capacity of the environment to provide food and other basic needs in exchange for demands placed by human communities on these ecological services, if the ecological footprint of the population exceeds biological capacity, then the situation is intolerable (Ewing et al. 2010).

Figure 1 Measures' differentiations between the ecological footprint and bio-capacity

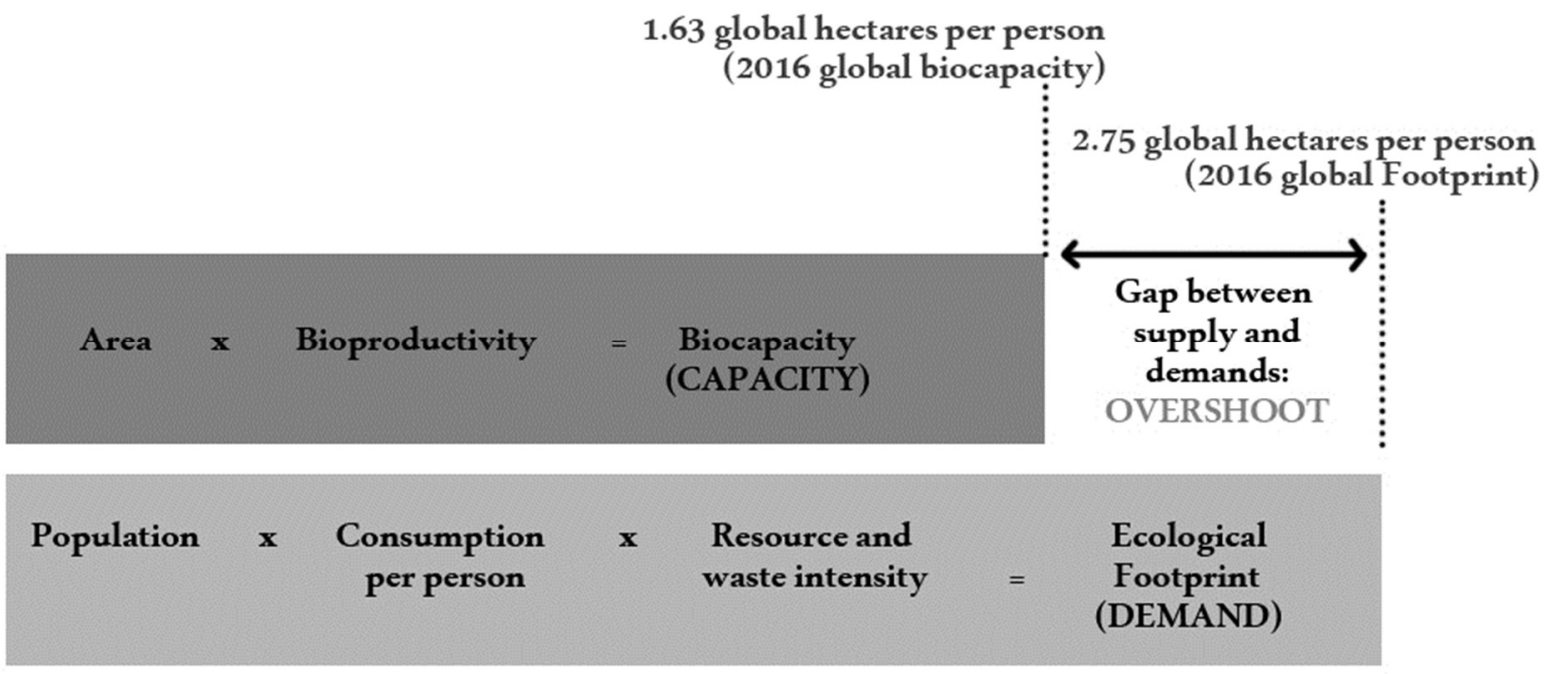

Source: Ewing et al. (2010) updated by authors

The total global human ecological footprint is 2.6 global hectares per person (gha/person), compared to the total global bio-capacity only 1.8 (gha/person) according to Ecological Footprint Atlas 2009 based on GreenFacts (2012). This excess means that humanity has already used 1.4 times the resources available to them, which is only possible for a short period, and the overrun for high-income countries is far more extreme than the global 
average. While the low-income countries have a typical footprint of 1.0 (gha/person), the average high-income countries is $6.1 \mathrm{ha} /$ person, as the United Kingdom averaged 6.12 (gha/person) and therefore we already need 3.4 planets to support the total world population of 6.68 million inhabitants for everyone have the living standards in the UK (GreenFacts, 2012). According to Global Footprint Network in 2016: global biocapacity is 1.63 global hectares per person (gha/person), and the global footprint is 2.75 global hectares per person (gha/person).

Ecological Footprint principles: The ecological footprint takes into consideration six types of land (Anielski and Wilson, 2005). The study of the ecological footprint dealt with four main categories of consumption: energy consumption (housing, transport, industrial, commercial), food, goods and services (Maguire \& et al., 2008). These data have been transferred to the six land categories (the areas used in the ecological footprint calculations).

The ecological footprint (EF) is divided as follows:

1. Energy Land (carbon absorption land): the land that will absorb $\mathrm{CO} 2$ emissions such as green areas and dense afforestation areas.

2. Agricultural lands (crops): the agricultural land required for the production of crops consumed by the individual.

3. Pastureland (grazing): It is grazing land areas for animals.

4. Forest lands: They are the land areas of forests required to produce wood and paper.

5. Fishing areas and seas: water areas for marine fish production.

6. Built-up area: The area of land needed to accommodate population and infrastructure.

\section{METHODS OF ECOLOGICAL FOOTPRINT MEASUREMENT}

- Include all areas of the land in the ecological footprint: in this way, data are collected from multiple sources through the agricultural, environmental and other reports. The area of productive land that is exploited by humans is then divided into population size. The ecological footprint (ha/ person) is produced. The following equation shows how to calculate the ecological footprint (Lenzen and Murray, 2003).

\section{Production of all land areas/ Population size $=$ Ecological Footprint (ha per person)}


- Through actual land areas, land disturbance assessment: In the calculation of the original ecological footprint; forest, pasture and cropland areas do not represent real land, but productive land must be used, average productivity calculated, and thus easy to compare the ecological footprint of different countries (United Nations Secretariat, 2000). The initial ecological footprint and biocapacity adopted at the international level were the same, but due to many changes caused by humans on earth such as construction of roads and buildings, have changed the natural setting which is considered in this method (calculation of the actual land areas without urbanization, utilities and infrastructure).

The following figure shows an example of a plot of land of 100 hectares. In the way of land disturbance, roads, quarries, mined areas, cleared areas and built-up land are removed. What remains is the ecological footprint (Lenzen and Murray 2003).

Figure 2 Areas removed from productive land when calculating the ecological footprint in a turbulent manner.

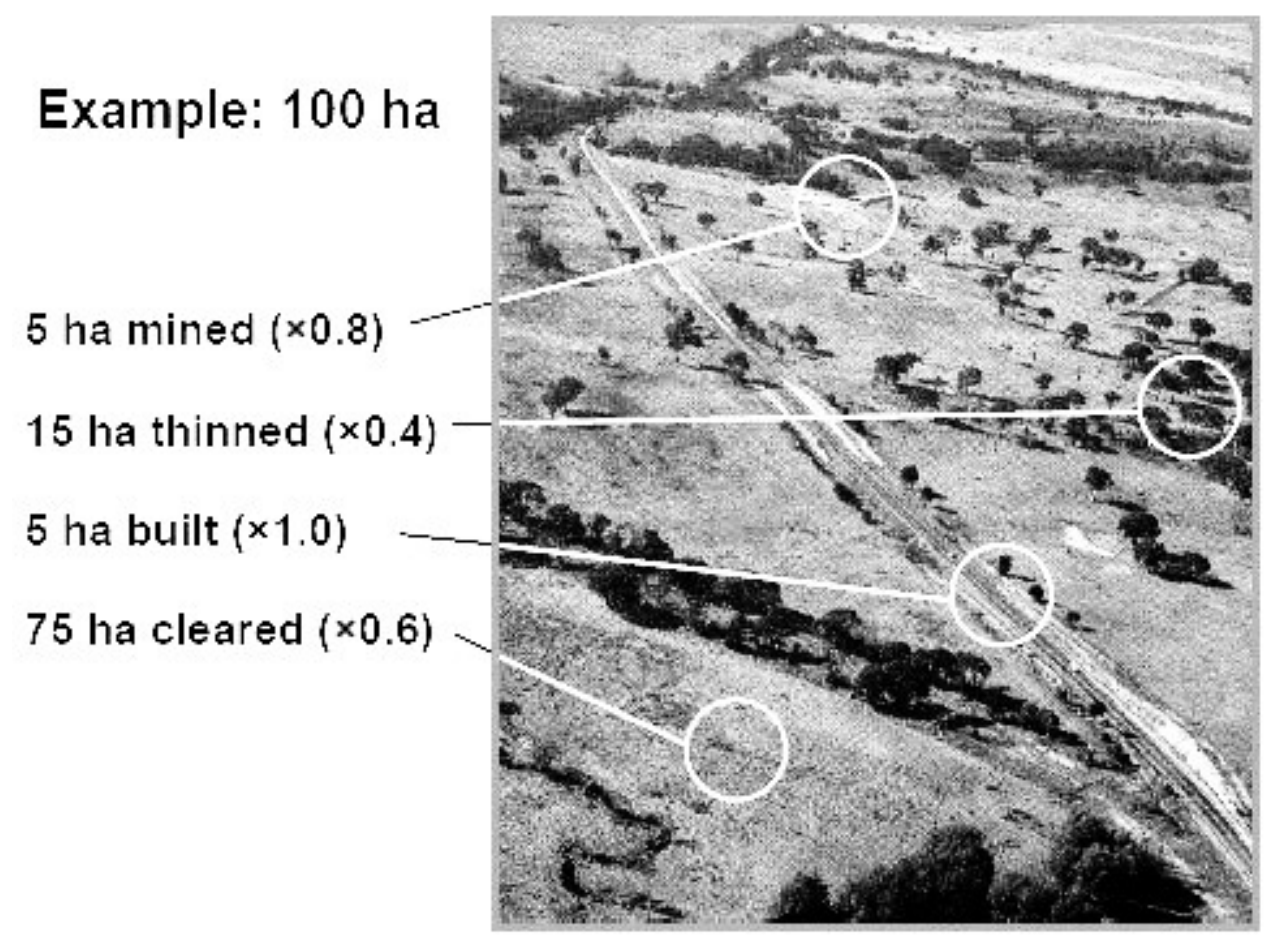

Source: Lenzen and Murray (2003).

- Land emission method - Inclusion of climate change impacts: The original ecological footprint method was only using emissions accounted from fossil fuels in their calculation, and was not taking into account, other greenhouse gas 
emissions, and emissions from other sources of land, industrial processes, waste and natural gas leak. In Australia, there is a policy for cleansing and transforming energy consumption into a land area with the so-called carbon sequestration or return to the land area from which it came, taking into account climatic and technological conditions. Thus, this method is combined between land use and land emissions, so it is necessary to take into account climate changes resulting from these harmful emissions (Lenzen \& Murray, 2003).

\section{DISCUSSION}

Special equations for National Ecological Footprint Calculation: those are done by studying economic flows such as production, investment, consumption and the calculation of imports and exports in order to know overall economic performance (Lenzen and Murray, 2003). In this method, calculation is based on the national GDP expressed by the extent of the success of the state or scope in the exploitation of its resources and energies as shown below:

\section{Gross national expenditure + Exports - Imports $=$ National Gross Domestic Product}

Total national expenditure and its role divided into the following uses:

- Private final consumption (family),

- Final government consumption,

- Gross fixed capital expenditure (investment)

- Changes in inventories.

Therefore, the ecological footprint according to the special consumption patterns (household consumption - government consumption - investment consumption), will have an impact on the gross national product. For example, the lesser the GDP indication will increase the value of the ecological footprint of individuals within the state.

Net Consumption: Our net environmental dependence is linked to our net consumption of natural resources. Therefore, the higher the net consumption, the greater the risk to the natural environment, although there are economic effects in the short run rather than the distant ones.

\section{Net Consumption $=$ Production + Import - Export}

a) Ecological Footprint and Biocapacity: Equations of the footprint calculation environment as presented in the Ecological Footprint Atlas 2010 (Ewing et al., 2010).

b) Farmland footprint: They are calculated according to the productivity rates of individuals and calculated by dividing the net production per capita on the 
maximum production rate of the land resource. Thus, the higher the net production per capita, the higher its ecological footprint. The following equations show the identification of the ecological footprint:

Maximum production rate $(\mathbf{k g} / \mathbf{h a})=$ Total resource productivity / resource capacity (area that the resource can exploit) (tonnes)

Net production of the supplier $=$ Actual resource productivity + Export - import

Net production per capita from supplier $=$ Net production of resource/ total population

Global Ecological Footprint $=$ Net production per capita $/$ maximum production rate $(\mathrm{kg} / \mathrm{ha})$

a) Carbon footprint: The amount of carbon dioxide produced by the individual through the exploitation of nature and assuming the person's output of carbon dioxide 6 tons, each 1 hectare of land absorbed 1.8 tons of carbon dioxide, 1 hectare of lakes $1 / 3$ tons of carbon dioxide $(\mathrm{CO} 2)$ of individual pollutants, by the following can be equated.

The quantity we get rid of pollution per person $=\underline{4.57 *(1-1 / 3)}$

\section{8 tons / ha}

It has also been shown that the amount discharged by land and sea from the pollution product $=1,693 \mathrm{gha} /$ person and calculated from the reciprocal equation.

Note: The greater the carbon footprint, the more negative ecological footprint becomes, and the gap between biocapacity and ecological footprint increases, which is the gap between the demand and supply for resources offered by the environment.

\section{RESULTS}

The role of ecological footprint in measuring the implications of existing land uses and activities: The ecological footprint is a measure of the impact of a particular society (through its consumption of resources to meet its needs and future aspirations) on the natural environment (Young, 2009). Therefore, there is a great relationship between the ecological footprint and the land use process. Kindly note that:

- Relationship between them is a direct relationship, the more urban land uses the greater negative impact on the natural environment.

- The larger volume of polluting industries with large emission volumes, the greater ecological footprint with a negative impact on the natural environment (EJOLT 2012).

- Ecological footprint is an important factor in determining the quality of endemic uses in the region in accordance with the Eco-privacy (European Commission, 2015). 
Figure 3 Relationship between Ecological Footprint and Human Development Index

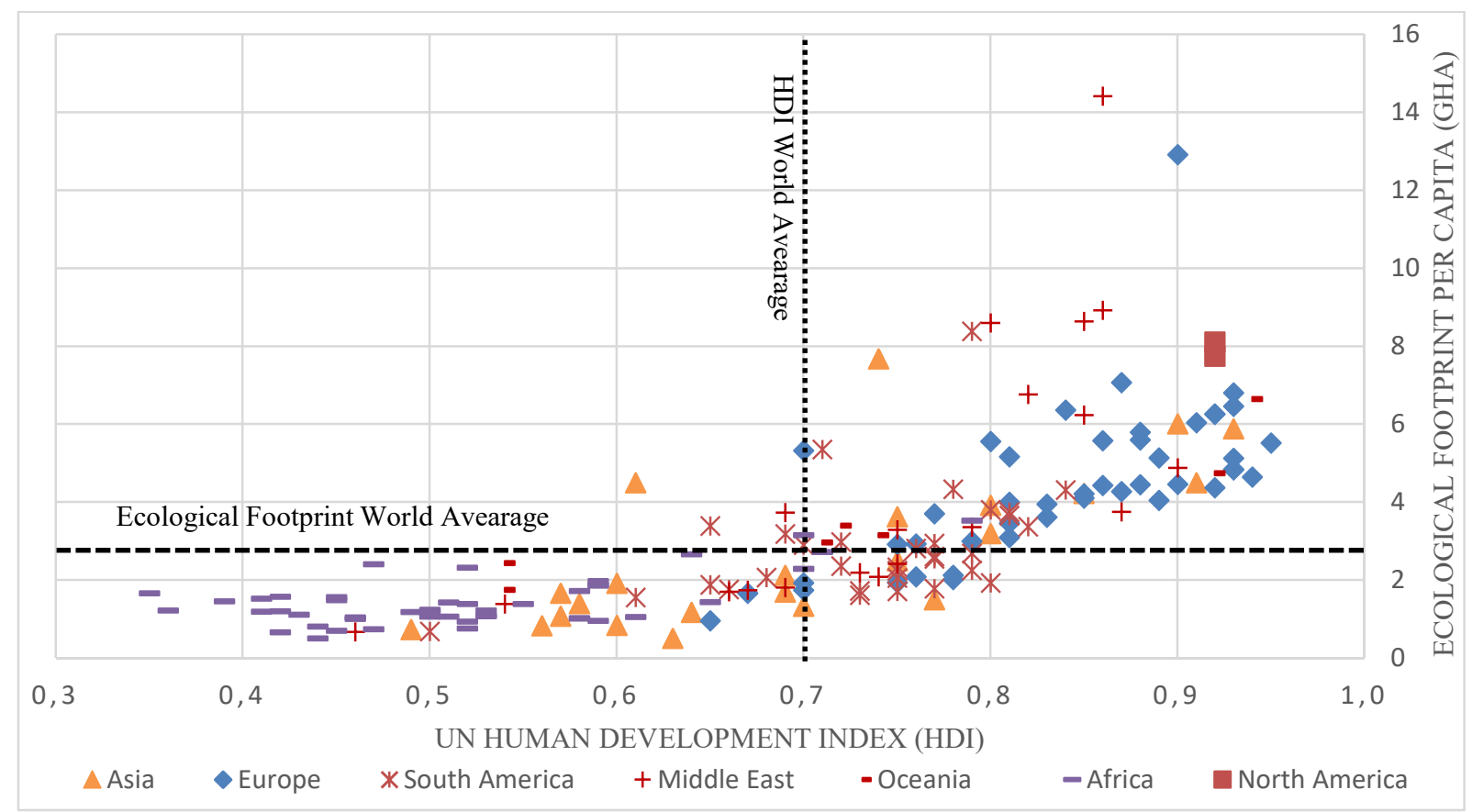

Source Authors based on (Global Footprint Network 2012).

Note: The higher the indicators of human development index, the greater the ecological footprint, as opposed to the countries where these indicators are low, and the ecological footprint is low as shown in figure 3.

As shown in figure 3 above, most European countries have a high human development index but exceed the limit of biodiversity. With an ecological footprint more than double its own biocapacity, The Visegrád Group countries well-being depends on ecological capacity from elsewhere. This means that as long as its ecological deficit is unaddressed, V4 are losing that biocapacity. Therefore, reducing its Ecological Footprint is vital for European competitiveness.

The Ecological Footprint possibly the most popular, comprehensive environmental indicator, which is an indicator of human utilization of renewable resources. However, the Ecological Footprint represents an original method of quantification of human use of natural resources, it builds on older concepts that relate human consumption of natural resources to the limited capacity of the natural surroundings. Before the term Ecological Footprint was invented, its authors used the term "appropriated carrying capacity" (Rees, 1992), clearly linking it to the concepts of "carrying capacity" (Hardin, 1976) and "human appropriation of net primary production" (Vitousek et al., 1986). The methodology was first introduced in the book Our Ecological Footprint (Wackernagel and Rees, 1996) and has evolved over time. 
"While it is still cheap to run an ecological deficit, if humanity's current levels of resource consumption continue, such a deficit will become an increasing liability for countries" (Wackernagel and Rees, 1996).

The Visegrád country profile is characterized by developing nations that have had some positive developments in the eco-invention and the share of employed people in foreign-held enterprises, although their level has stayed quite low. Under these situations, they hold a substantial potential to proceed to a higher class of ecological footprint, if they as well record a significant growth in the GDP per capita over the following stage.

The challenges posed present significant opportunities for Europe. Therefore, V4 countries can be part of leading countries guiding the world by investing in innovations in the areas of food, health, nature management, mobility, shelter, and green energy future. For instance, new innovation technology will not only be needed in V4 but the entire European Union and the world as a whole. V4 can be part of guiding the world with technologies that drive sustainability and can build transport and city infrastructure that facilitates rather than thwarts the transition to a sustainable future. The Ecological Footprint can help Visegrád to determine whether its actions get it closer to its goals.

The ecological characteristics of Visegrád group have high variability in the ecological footprint such as, former socialist countries, less developed, slightly higher level of employment in foreign-controlled enterprises (slightly above the EU average), but low ecoinnovation level. Both factors have received close to positive developments, which is why we think that they have a substantial potential to displace into a higher class of ecological footprint, if they also record GDP per capita growth in the following stop.

Figure 4 Ecological Footprint and Human Development Index in Visegrád four

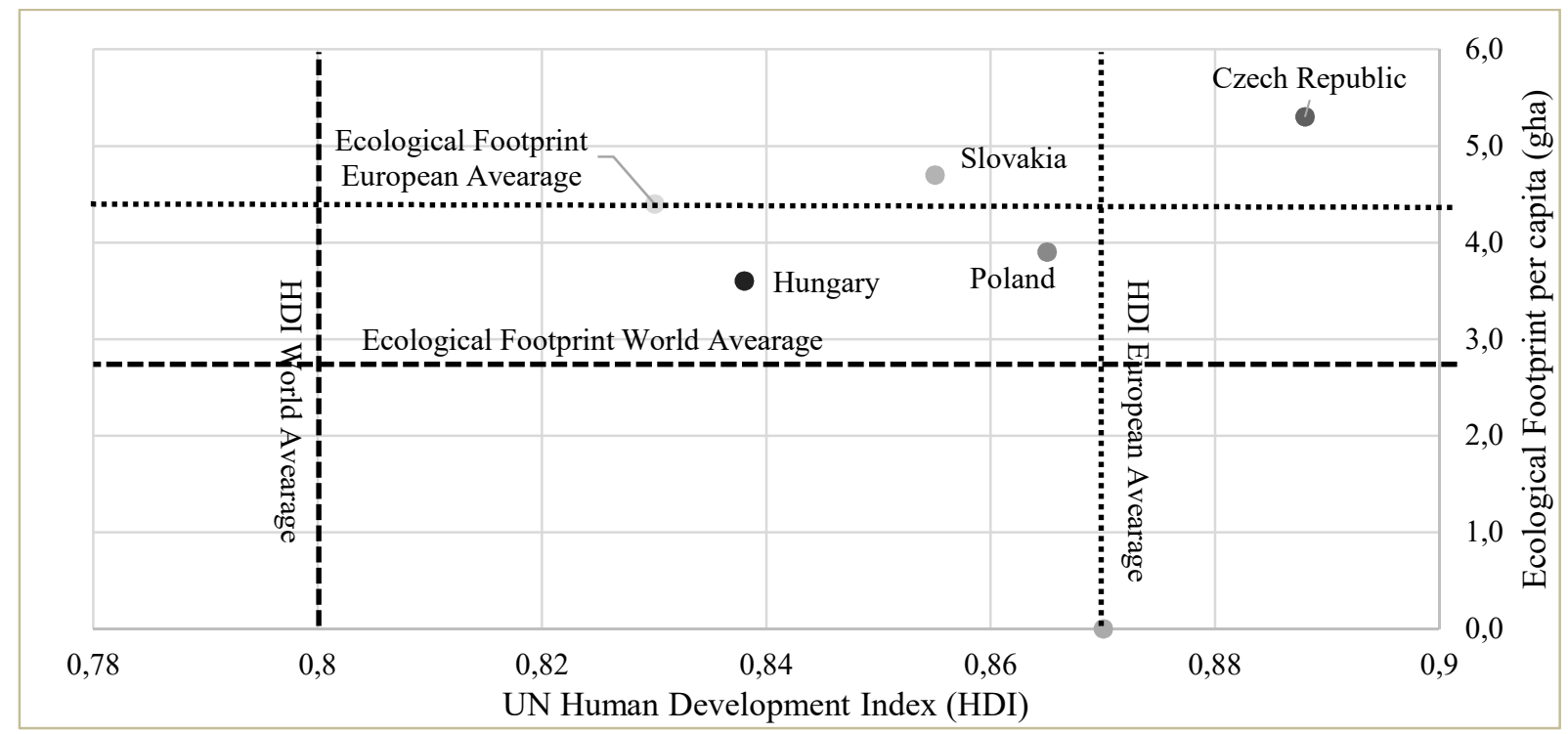

Source: authors 
The first pillar of sustainable development - ecological balance - concentrates on the human interaction with the environment. The major goal is to minimize the negative impact on the environment as well as to protect non-renewable resources. It may be achieved only if the natural resources would be consumed at a pace, which guarantees that resources will last for future generations. Biodiversity maintenance, atmospheric stability and ecosystems stability are other vital aspects of ecological sustainability.

The second one - economic growth - is linked to the business profits as well as to social and environmental costs and covers a wide spectrum of related economic issues such as externalities, public goods, economics of scale, market structures, information asymmetry, public choice and others.

The last pillar - social progress - concentrates on the quality-of-life development. Social sustainability comprises distributional equity, adequate provision of social services (such as health and education), gender equity, and political accountability and participation.

According to Milan Kucan, Politician, lawyer, Former President the Republic of Slovenia; that one the key issues in such a dialogue is the need to find a balance between labour and capital. If globalization remains limited to the globalization of capital, as is currently the case, and fails to include the globalization of responsibility for social cohesion, for ecological balance, and for the reduction of the gap between the rich and the poor, then people's impression that their physical, social and national existence is at risk will grow stronger. For central Europe, a relatively small area harbouring a great diversity of states, nations, languages, cultures, religions and civilizations, these dilemmas pose an even greater challenge.

Assessing Visegrad countries solely in terms of their Ecological Footprints, they have, on average, lower demands on renewable resources than the whole group of developed countries (4.4 gha versus 5.3 gha, all data per capita). Hungary and Poland have the lowest Ecological Footprints not only within the Visegrad group, but they are top performers among all the 26 developed countries. Hungary's Ecological Footprint (3.6 gha) is only half that for the United States (7.2 gha), while the Czech Republic's (5.3 gha) is somewhere in between. Clearly, there are significant differences in consumption demands in different countries. Once we extend this to all the 149 countries, the range is even wider, starting from around 0.5 gha and going up to 11.7 gha. What is interesting, however, is the position of developed countries (relative to the positions of other, mostly developing, countries) in the Ecological Footprint vis-à-vis their position in the EPI. While in the EPI, all the 26 developed countries were among the first 50 countries, none of these countries are among the first 100 countries in the 
Ecological Footprint. It is difficult to reconcile the results where a group of 26 developed countries have the top 'environmental performance' in the world (EPI), yet they consume the highest amounts of renewable resources (Ecological Footprint).

As for the second interpretation of the Ecological Footprint concept, most developed countries again rank at the bottom of the table (though a few countries with large areas relative to their populations, such as Canada and Australia, rank very high). All the Visegrad countries show an ecological deficit (rather than a reserve), having higher demands on renewable resources than can be provided by the biologically productive area of their respective territories. In fact, only 6 out of the 26 developed countries show an ecological reserve. Should the Ecological Footprint concept be interpreted as an indicator of sustainability, then most of the developed countries do not live within the carrying capacities of their environments and are not on a sustainable trajectory.

The Ecological Footprint concept looks intuitive and is appealing as a communication tool for showing human demands on nature. However, both the concept of the Ecological Footprint and its methodology are challenged (van den Bergh and Verbruggen, 1999). First, the Ecological Footprint is based on the current technological level and does not reflect technological progress. This is mainly the case with the carbon footprint - fossil fuel use is converted to bio productive area using an area of forest needed to sequestrate emitted $\mathrm{CO} 2$. This arguably overestimates the Ecological Footprint since it does not consider other options for conversion of fossil fuel use to a bio productive area, options that might be expensive yet economical in terms of required bio productive area. The second challenge relates to the question of whether the Ecological Footprint concept has a meaningful application at a lower than global level. More specifically, given the unequal distribution of the world population and natural resources, it is questionable whether we should really expect Japan to live within its biocapacity of 0.6 gha (all data per capita). With a moderate Ecological Footprint (4.2 gha), Japan shows an ecological deficit (3.6 gha), while Canada shows a large surplus (8.5 gha) even with the fourth highest Ecological Footprint (6.4 gha) among the 26 developed countries. Indeed, it would be difficult for Canada not to live within its large biocapacity (14.9 gha).

\section{CONCLUSION}

Land use assessment methods are concerned with different periods and phases in the land use planning process, where the ecological footprint scale can be used in the initial planning 
stages to assess the current situation, especially when compared with the HDI to measure the relationship between environmental, and developmental impacts. It shows that the ecological footprint focuses on the elements of the earth, and how human uses are influenced by them. They have ecological comparison methods related to biological ability, a measure of human damage to the environment, and development comparison through their relation to human development, and the extent of environmental stress. Representing a unique benchmark for linking the environmental and developmental field. The higher indicators of human development index, as Czechia in our case, the greater ecological footprint, as opposed to the countries where these indicators are low, and the ecological footprint is low such as Hungary and Poland, where they are compared to European average. Moreover, if we would compare to world average, they all exceed the average and they are using more biocapacity.

\section{SUMMARY}

Land use planning is the key for the developmental plans, it is necessary to assess the current situation to have an effective plan later. Creating regional plans more effective is not that easy, as in most cases they do not follow integrated system of land-use planning that enhance urban settlement in defining the vision and goals of their policies. Consequently, there was a need to find a proper measurement tool to assist the decision making for setting effective regional plans for national and regional land use planning, with a sustainable understanding of the regions and their opportunities and challenges, also it would be good if that tool use the main elements of sustainable (environment, economics, social). The EF is the most appropriate evaluation method for measuring the impacts on the different types of land uses as well as the possibility of measuring their developmental implications, as there is a significant relation between it and human development index to move with it from being a pure environmental indicator to be a developmental indicator. Here, the EF is referred to as modern standards suitable for land use assessment at existing and proposed stages of urban development plans. The research methodology applied in this study was the interpretation and understanding in a comprehensive way the EF as a tool for land use planning on national and regional level. The novelty of our research is derived from the fact that there has not been a research on this issue relating to environmentally developmental recommendations on Visegrád countries based on their EF. The main method was qualitative research study through documents and reports reviews, and their applications on Visegrád countries. This study also attempts to use a new tool for national and regional land use planning approaches by reviewing the EF as tools for evaluating regional land use in their current situation and in the stages of preparation of urban plans. Firstly, the study had an overview on the definitions of EF and biocapacity. Next, it focused on the relation between them, and their principles. Finally, the researchers illustrated some measurement methods and equations of EF, with an application of Visegrád four.

Special equations for National Ecological Footprint Calculation: those are done by studying economic flows such as production, investment, consumption and the calculation of imports and exports in order to know overall economic performance. In this method, calculation is based on the national GDP expressed by the extent of the success of the state or scope in the exploitation of its resources and energies as: [Gross national expenditure + Exports - Imports $=$ National Gross Domestic Product]. Therefore, the ecological footprint according to the special consumption patterns (household consumption - government consumption - investment consumption), will have an impact on the gross national product. For example, the lesser the GDP indication will increase the value of the ecological footprint of individuals within the state. Based on the following methods: a) Ecological Footprint and Biocapacity; b) Farmland footprint; and c) Carbon footprint. The greater the carbon footprint, the more negative ecological footprint becomes, and the gap between biocapacity and ecological footprint increases, which is the gap between the demand and supply for resources offered by the environment.

The role of ecological footprint in measuring the implications of existing land uses and activities: The ecological footprint is a measure of the impact of a particular society (through its consumption of 
resources to meet its needs and future aspirations) on the natural environment. Therefore, there is a great relationship between the ecological footprint and the land use process. Kindly note that: 1) Relationship between them is a direct relationship, the more urban land uses the greater negative impact on the natural environment; 2) The larger volume of polluting industries with large emission volumes, the greater ecological footprint with a negative impact on the natural environment; and 3) EF is an important factor in determining the quality of endemic uses in the region in accordance with the Eco-privacy.

The higher the indicators of HDI, the greater the EF, as opposed to the countries where these indicators are low, and the EF is low. Indicated previously, most European countries have a high HDI but exceed the limit of biodiversity. With an EF more than double its own biocapacity, The Visegrád Group countries well-being depends on ecological capacity from elsewhere. This means that as long as its ecological deficit is unaddressed, V4 are losing that biocapacity. Therefore, reducing its EF is vital for European competitiveness.

The EF possibly the most popular, comprehensive environmental indicator, which is an indicator of human utilization of renewable resources. However, the Ecological Footprint represents an original method of quantification of human use of natural resources, it builds on older concepts that relate human consumption of natural resources to the limited capacity of the natural surroundings. Before the term EF was invented, its authors used the term "appropriated carrying capacity", clearly linking it to the concepts of "carrying capacity" and "human appropriation of net primary production".

The Visegrád country profile is characterized by developing nations that have had some positive developments in the eco-invention and the share of employed people in foreign-held enterprises, although their level has stayed quite low. Under these situations, they hold a substantial potential to proceed to a higher class of EF, if they as well record a significant growth in the GDP per capita over the following stage.

The challenges posed present significant opportunities for Europe. Therefore, V4 countries can be part of leading countries guiding the world by investing in innovations in the areas of food, health, nature management, mobility, shelter, and green energy future. Perhaps, new innovation technology will not only be needed in V4 but the entire European Union and the world as a whole. V4 can be part of guiding the world with technologies that drive sustainability and can build transport and city infrastructure that facilitates rather than thwarts the transition to a sustainable future. The EF can help Visegrád to determine whether its actions get it closer to its goals.

The ecological characteristics of Visegrád group have high variability in the ecological footprint such as, former socialist countries, less developed, slightly higher level of employment in foreign-controlled enterprises (slightly above the EU average), but low eco-innovation level. Both factors have received close to positive developments, which is why we think that they have a substantial potential to displace into a higher class of ecological footprint, if they also record GDP per capita growth in the following stop. Land use assessment methods are concerned with different periods and phases in the land use planning process, where the ecological footprint scale can be used in the initial planning stages to assess the current situation, especially when compared with the HDI to measure the relationship between environmental, and developmental impacts. It shows that the EF focuses on the elements of the earth, and how human uses are influenced by them. They have ecological comparison methods related to biological ability, a measure of human damage to the environment, and development comparison through their relation to human development, and the extent of environmental stress. Representing a unique benchmark for linking the environmental and developmental field. The higher indicators of human development index, as Czechia in our case, the greater ecological footprint, as opposed to the countries where these indicators are low, and the EF is low such as Hungary and Poland, where they are compared to European average. Moreover, if we would compare to world average, they all exceed the average and they are using more biocapacity.

\title{
Acknowledgement
}

We would like to show our gratitude to Ebtehal Abdelmoity, Assistant professor; Walid Bayomy, Ph.D., Cairo University for sharing their pearls of wisdom with us.

\section{REFERENCES}

\author{
Anielski, M., \& Wilson, J. (2005). Ecological Footprints of Canadian Municipalities and \\ Regions. The Canadian Federation of Canadian Municipalities. Avenue, Edmonton, \\ Alberta, Canada: Anielski Management Inc.
}


Borucke, M., \& et al. (2011). The National Footprint Accounts. USA: Global Footprint Network.

Collins A. (2017). Ecological footprint, in the International Encyclopedia of Geography: People, the Earth, Environment, and Technology, edited by Douglas Richardson, et al. Oxford, UK: John Wiley and Sons, Ltd. Pages:1606-1608.

Ecological Footprint Atlas (2009). Ecological Footprint Atlas. Global Footprint Network, Research And Standards Department.

EJOLT. (2012). ecological-footprint. Retrieved 02 12, 2013, from ejolt: http://www.ejolt.org/ecological-footprint

European Commission (2015). Final Impact Assessment. Retrieved 9 20, 2015, from European Commission: http://ec.europa.eu/governance/impact/ia_carried_out/cia 2012 en.htm

Ewing, B., Reed, A., Galli, A., Kitzes, J., \& Wackernagel, M. (2010). calculation methodology for the national Footprint accounts, 2010 EditIon. Oakland, CA: Global Footprint Network.

Global Footprint Network. ( April 2010). The Ecological Wealth of Nations. Oakland, California, USA: Global Footprint Network.

Global Footprint Network. (2012, October 12). Global Footprint Network. Retrieved March 29, 2013, from Global Footprint Network: http://www.footprintnetwork.org/en/index.php/GFN/page/glossary/

GreenFacts. (2012). GreenFacts Scientific Board. Retrieved May 7, 2015, from GreenFacts: http://www.greenfacts.org/glossary/abc/biocapacity.htm

Goodall, B. (1987). Dictionary of Human Geography. England: Penguin Books.

Ira, V. (2001). Social, economic and environmental dimension of sustainable development in protected areas. Ekologia (Bratislava). Vol. 20, Supplement 3/2001, p. 205-316.

Lenzen, M., \& Murray, S. A. (2003). The Ecological Footprint - Issues and Trends, Sydney: The University of Sydney.

Maguire, C; Best; Aaron; Giljum, S; Simmons, C; Blobel, D; Lewis, K; Hammer, M; Cavalieri, S; and Lutter, S (2008). Potential of the Ecological Footprint for monitoring environmental impacts from natural resource use. European Commission, DG Environment.

United Nations Secretariat (2000). International Classification of Activities for Time Use Statistics, Expert Group Meeting on Methods for Conducting Time-Use Surveys, 2327 October 2000, New York.

Vasa, L., Angeloska, A., Trendov, N. (2018). Comparative analysis of circular agriculture development in selected Western Balkan countries based on sustainable performance indicators. Economic Annals-XXI 168 (11-12) pp. 44-47.

Wackernagel and Rees. (1996). Our Ecological Footprint. In M. Wackernagel, \& W. E. Rees, Our Ecological Footprint: Reducing Human Impact on The Earth (p. 164). Canada: New Society Publisher.

Young, H. (2009). Centre for Environmental Management,Land use and biodiversity relationships. United Kingdom: School of Geography, University of Nottingham, Nottingham. 